\title{
The Aurora B kinase activity is required for the maintenance of the differentiated state of murine myoblasts
}

\author{
G Amabile ${ }^{1,2}$, AM D’Alise ${ }^{1}$, M lovino ${ }^{1}$, P Jones ${ }^{3}$, S Santaguida ${ }^{4}$, A Musacchio ${ }^{4}$, S Taylor ${ }^{5}$ and R Cortese ${ }^{\star, 1}$
}

Reversine is a synthetic molecule capable of inducing dedifferentiation of $\mathrm{C2}_{2} \mathrm{C} 2$, a murine myoblast cell line, into multipotent progenitor cells, which can be redirected to differentiate in nonmuscle cell types under appropriate conditions. Reversine is also a potent inhibitor of Aurora B, a protein kinase required for mitotic chromosome segregation, spindle checkpoint function, cytokinesis and histone $\mathrm{H} 3$ phosphorylation, raising the possibility that the dedifferentiation capability of reversine is mediated through the inhibition of Aurora B. Indeed, here we show that several other well-characterized Aurora B inhibitors are capable of dedifferentiating $\mathrm{C}_{2} \mathrm{C} 12$ myoblasts. Significantly, expressing drug-resistant Aurora B mutants, which are insensitive to reversine block the dedifferentiation process, indicating that Aurora B kinase activity is required to maintain the differentiated state. We show that the inhibition of the spindle checkpoint or cytokinesis per se is not sufficient for dedifferentiation. Rather, our data support a model whereby changes in histone $\mathrm{H} 3$ phosphorylation result in chromatin remodeling, which in turn restores the multipotent state.

Cell Death and Differentiation (2009) 16, 321-330; doi:10.1038/cdd.2008.156; published online 31 October 2008

Lineage-restricted cells can be reprogramed to a state of pluripotency by several different manipulations, including somatic cell nuclear transfer ${ }^{1}$ embryonic stem cell (ES) fusion $^{2}$ or even by cotransfection of four specific transcription factors. ${ }^{3-5}$ In particular, C2C12 myoblasts can be reprogramed to dedifferentiate into multipotent progenitor cells that can be redirected to other cell types under appropriate stimuli, including the ectopic expression of Msx1 gene, ${ }^{6}$ or by exposure to chemical compounds such as reversine. $^{7}$

Reversine, a purine derivative, was identified by virtue of its ability to increase the plasticity of $\mathrm{C} 2 \mathrm{C} 12$ myoblasts. This compound interferes with the normal differentiation pathway causing $\mathrm{C} 2 \mathrm{C} 12$ cells to dedifferentiate to a pluripotent state. More recently, it was demonstrated that reversine can differentiate human fibroblasts into skeletal muscle cells in vitro and in vivo, ${ }^{8}$ suggesting that reversine is capable of also reprograming primary somatic cells to a state of increased plasticity. We recently discovered that reversine is also a potent Aurora kinase inhibitor. ${ }^{9}$ The Auroras are serine/ threonine kinases required for multiple aspects of mitosis in eukaryotic cells. Aurora A promotes centrosome maturation and spindle assembly, ${ }^{10}$ whereas Aurora $B$ is required for histone $\mathrm{H} 3$ phosphorylation, chromosome segregation, ${ }^{11}$ the spindle assembly checkpoint and cytokinesis. ${ }^{12}$
Evidence is emerging that the role of Aurora $B$ is not restricted to mitosis and cell division. A key substrate of Aurora $B$ is serine 10 (ser10) of histone $\mathrm{H} 3$, and although this phosphorylation event was originally thought to be involved in chromosome condensation, it now appears that it dissociates HP1 proteins from methylated histone $\mathrm{H} 3$ (K9me3) at the onset of mitosis. ${ }^{13,14}$ Indeed, histone $\mathrm{H} 3$ (ser10) is an important element in the combinatorial histone code that is associated with both active and inactive chromatin. ${ }^{15}$ At the onset of mitosis, phospho-Ser10-H3 is responsible for the ejection of HP1 proteins from their binding site on chromatin, probably through a steric hindrance. ${ }^{13,14}$ Furthermore, it was demonstrated that the modifications of histone $\mathrm{H} 3$ and consequently the redistribution of HP1s are linked to chromatin reorganization and to cellular dedifferentation. ${ }^{16}$ Consistent with a role for Aurora B in chromatin structure, it was recently shown that Aurora $B$ is required to remodel chromatin during postmitotic cell differentiation of mesenchymal stem cells and in the transition of B cell to plasma cells. ${ }^{17}$

The ability of reversine to both dedifferentiate $\mathrm{C} 2 \mathrm{C} 12$ cells and to inhibit Aurora B raised the possibility that its dedifferentiation capability is mediated through Aurora B. Here, we present the evidence that in addition to reversine, several other Aurora B inhibitors can dedifferentiate $\mathrm{C} 2 \mathrm{C} 12$ myoblasts. By using drug-resistant Aurora B mutants, we

\footnotetext{
${ }^{1}$ CEINGE Biotecnologie Avanzate, Naples, Italy; ${ }^{2}$ Department of Cellular Biotechnology and Hematology, University of Rome La Sapienza, Rome, Italy; ${ }^{3}$ RBMM Merck Research Laboratory, Pomezia, Italy; ${ }^{4}$ Department of Experimental Oncology, European Institute of Oncology, Milan, Italy and ${ }^{5}$ Faculty of Life Sciences, University of Manchester, Manchester, UK

${ }^{*}$ Corresponding author: R Cortese, Medical Biotechnology, CEINGE Biotecnologie Avanzate, Via Comunale Margherita 482, Naples 80131, Italy. Tel: + 393358104 832; Fax: + 3908174636 50;

E-mail: cortese@ ceinge.unina.it

Keywords: dedifferentiation; reversine; Aurora B; myoblasts

Abbreviations: ES, embryonic stem cells; ap2, adipocyte fatty acid-binding protein; LPL, lipoprotein lipase ; ALP, alkaline phosphatase; NMMII, nonmuscle myosin II heavy chain ; MEK, mitogen-activated extracellular signal-regulated kinase; ADM, adipogenic-differentiating medium; ODM, osteogenic-differentiating medium; MRFs, muscle regulatory factors; Id(s), inhibitor of differentiation(s); Myf5, myogenic factor 5; Lys, lysine; Ser, serine; p, phospho; me, methyl

Received 18.6.08; revised 19.9.08; accepted 19.9.08; Edited by G Cossu; published online 31.10.08
} 
provide compelling evidence that the effects of reversine are mediated through Aurora B as opposed to an off-target effect. Furthermore, we demonstrate that reversine remodels the chromatin associated with several genes that are induced or repressed during the phenomenon of dedifferentiation. Altogether, our data suggest a novel role for the Aurora B kinase in gene regulation and in the maintenance the differentiated state.

\section{Results and Discussion}

Aurora kinase inhibitors reprogram $\mathbf{C 2 C 1 2}$ myoblasts. Reversine inhibits several proteins including MEK1, nonmuscle myosin II (NMMII), Aurora A and B. ${ }^{9}$ On the basis of several indirect lines of evidence, it was suggested that reversine induces dedifferentiation by the simultaneous inhibition of MEK1 and of NMMII. ${ }^{18}$ However, as reversine is a potent Aurora inhibitor, we wanted to determine whether the inhibition of Aurora A and/or B may be involved in the dedifferentiation process. To do this, we asked whether a panel of other Aurora kinase inhibitors could dedifferentiate $\mathrm{C} 2 \mathrm{C} 12$ cells, reasoning that structurally diverse inhibitors should have different spectra of off-target effects. ${ }^{19} \mathrm{We}$ chose to use hesperadin, which is relatively selective for Aurora $B,{ }^{20} V X-680$, which is a dual Aurora A/B inhibitor ${ }^{21}$ and $M L N-8054$, which is relatively selective for Aurora $A{ }^{22}$ Significantly, hesperadin, VX-680 and MLN-8054 induced dedifferentiation of $\mathrm{C} 2 \mathrm{C} 12$ myoblasts (Figure 1). C2C12 cells were treated with compounds for $72 \mathrm{~h}$ as indicated; after this, the drug-containing media were removed and the cells were cultured in drug-free medium suitable for the development of adipocytes (adipogenic-differentiating medium; ADM) and osteoblasts (osteogenic-differentiating medium; ODM), respectively. After 7 days, cells were stained with Oil Red $O$ reagent to evaluate the presence of adipocytes or for alkaline phosphatase to evaluate the presence of osteoblasts (Figure 1a). In addition, to have a quantitative analysis of the dedifferentiation phenomenon, we used a fluorescent substrate system to evaluate the amount of lipid droplets in the case of adipocytes and the alkaline phosphatase activity in the case of osteoblasts (Figure $1 \mathrm{~b}$, see Materials and Methods also).

Furthermore, we decided to investigate also the expression of specific markers of both osteoblast and adipocyte differentiation. In particular, after the treatment with $500 \mathrm{nM}$
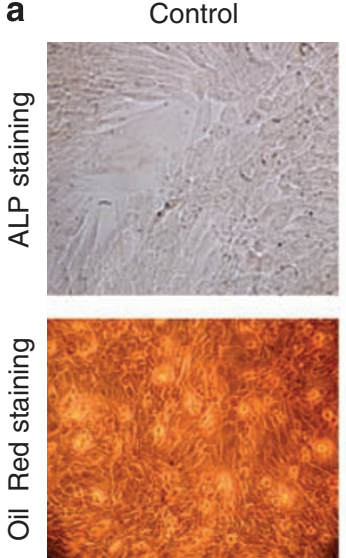

ALP activity
Reversine
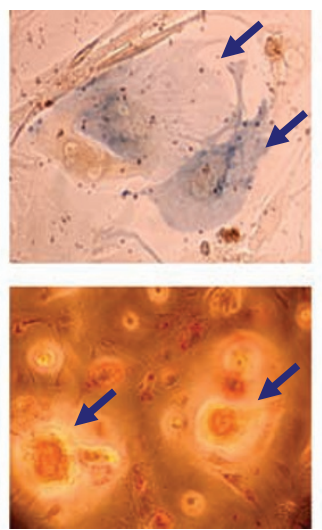

VX-680
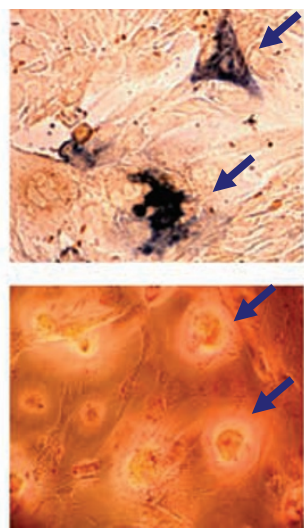

$72 \mathrm{hr}$ treatment $(500 \mathrm{~nm})$
Hesperadin
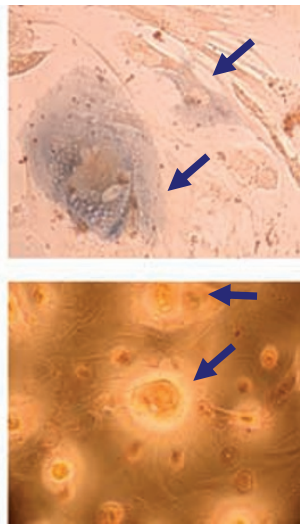

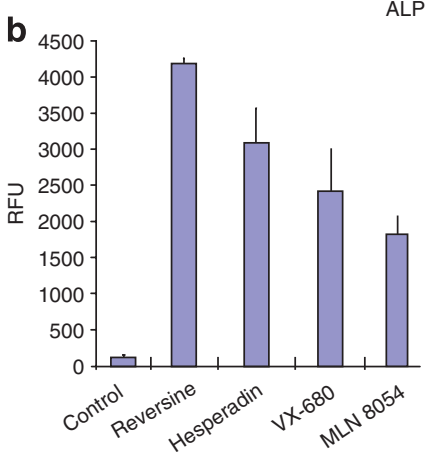

$72 \mathrm{hr}$ treatment $(500 \mathrm{~nm})$

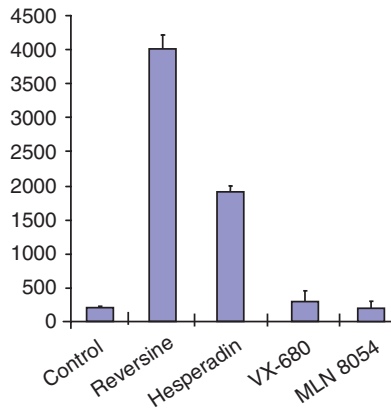

$72 \mathrm{hr}$ treatment $(50 \mathrm{~nm})$

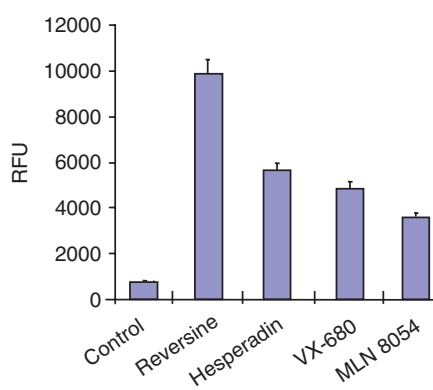

$72 \mathrm{hr}$ treatment $(500 \mathrm{~nm})$

Adipo Red assay

Figure 1 Aurora kinases inhibitors induce $\mathrm{C} 2 \mathrm{C} 12$ dedifferentiation. (a) $\mathrm{C} 2 \mathrm{C} 12$ cells were treated for $72 \mathrm{~h}$ with $500 \mathrm{nM}$ of reversine, hesperadin and VX-680. Alkaline phoshatase and Oil Red $O$ stainings were performed after 7 days of exposure to osteogenic-differentiating (ODM) and to adipogenic-differentiating media (ADM), respectively. The arrows indicate cells positive for Alkaline phosphatase (upper panel) and for lipid droplets content (lower panel) (b) $\mathrm{C} 2 \mathrm{C} 12 \mathrm{cells}$ were treated for $72 \mathrm{~h}$ with 500 or $50 \mathrm{nM}$ of reversine, hesperadin, VX-680 and MLN-8054. Then, cells were cultured in ODM and ADM media as indicated. ALP activity of C2C12 cells after the treatment was assayed using a fluorescent substrate system and the results were expressed in relative fluorescence units (RFUs). Quantitative analysis of adipocyte differentation was assayed with AdipoRed reagent to evaluate the lipids droplets content. The histograms show the RFUs measured with excitation at $485 \mathrm{~nm}$ and an emission at $572 \mathrm{~nm}$ 
of each compound and the exposure for 1 week to differentiating media, we analyzed the expression of osteopontin and collagen type 1 for the osteoblasts and the expression of the adipocyted fatty acid-binding protein (ap2) and of lipoprotein lipase (LPL) for the adipocytes. In Figure 2, we show that the treatment with the Aurora kinase inhibitors caused a relevant increase of these markers strengthening the notion that reversine-treated myoblasts can be induced to differentiate into other cell types.

Among the Aurora kinase inhibitors tested, reversine and hesperadin were very potent inducers of dedifferentiation, whereas MLN-8054 and VX-680 were only active at significantly higher concentration (Figure 1b). Interestingly, reversine and hesperadin are low nanomolar inhibitors of Aurora B kinase (S Santaguida and A Musacchio, unpublished observations, and Figure 3 ), and their effect on cultured cells is mainly because of the inhibition of Aurora B kinase. By contrast, when using VX-680 and MLN-8054, on cultured cells, the predominant phenotype from these drugs is the appearance of monopolar spindles, a hallmark of Aurora A inhibition (A Musacchio and $S$ Santaguida, unpublished observations, and Manfredi et al..$^{22}$ and Girdler et al. ${ }^{23}$ Thus, the spectrum of inhibitor potencies suggests that Aurora B kinase rather than $A$ might be the target of reversine in the dedifferentiation program

Importantly, although reversine inhibits MEK1 and NMMII, ${ }^{18}$ hesperadin and VX680 are not particularly potent against these two enzymes (Supplementary Figure 1), indicating that the inhibition of MEK1 and NMMII is not necessary for $\mathrm{C} 2 \mathrm{C} 12$ dedifferentiation.

Drug-resistant Aurora B kinase mutants block the dedifferentiation capabilities of reversine. The fact that multiple inhibitors of Aurora B can dedifferentiate $\mathrm{C} 2 \mathrm{C} 12$ cells is consistent with the notion that Aurora B activity is required to maintain the myoblasts in the differentiated state. However, although unlikely, we cannot rule out the possibility that all these inhibitors share a common 'off-target' enzyme. Therefore, to exclude this possibility, we set out to express drug-resistant Aurora B mutants in $\mathrm{C} 2 \mathrm{C} 12$ cells and ask whether this expression blocked reversine-induced dedifferentiation. We reasoned that if the dedifferentiation a

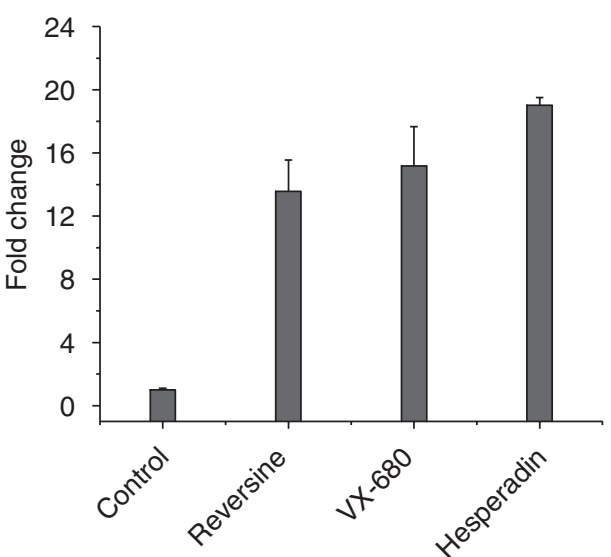

b

Adipocyte fatty acid-binding protein (ap2)

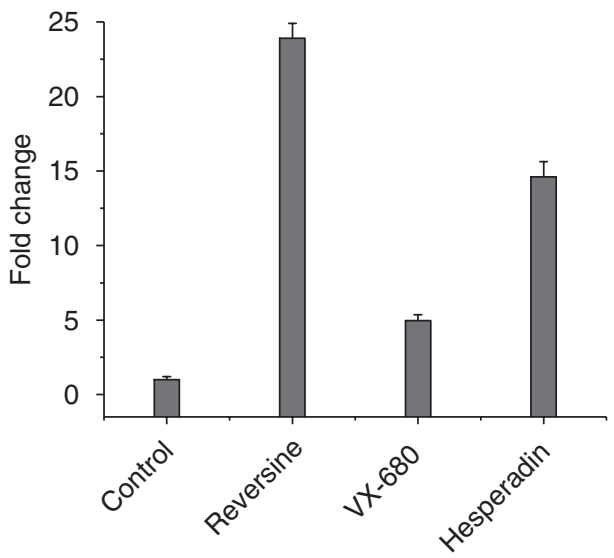

Collagen Type 1

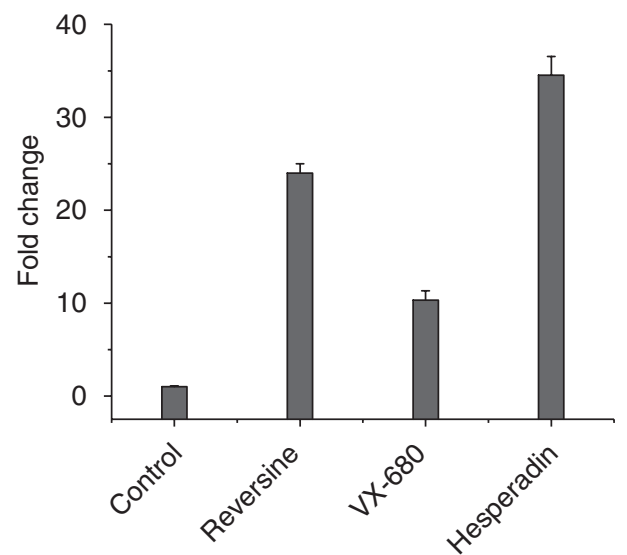

Lipoprotein lipase (LpL)

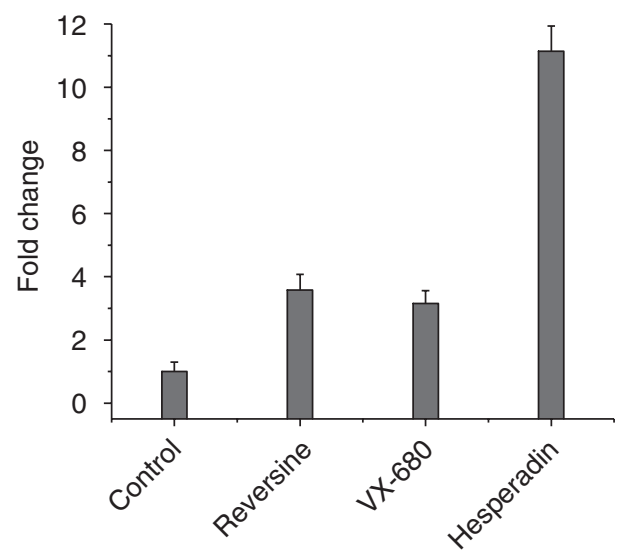

Figure 2 The use of Aurora kinases inhibitor induces the initiation of osteogenic and adipogenic program. (a) qRT-PCR for osteogenic (osteopontin and collagen type 1) and (b) adipogenic (adipocyte fatty acid-binding protein and lipoprotein lipase) genes was performed on $\mathrm{C} 2 \mathrm{C} 12$ cells treated with $500 \mathrm{nM}$ reversine, VX-680 and hesperadine, and then cultured in osteogenic-differentiating (ODM) and adipogenic-differentiating media (ADM) (as described in Materials and Method section). Genes mRNA levels were normalized using GAPDH. Untreated $\mathrm{C} 2 \mathrm{C} 12$ cells were used to calculate the fold enrichment 


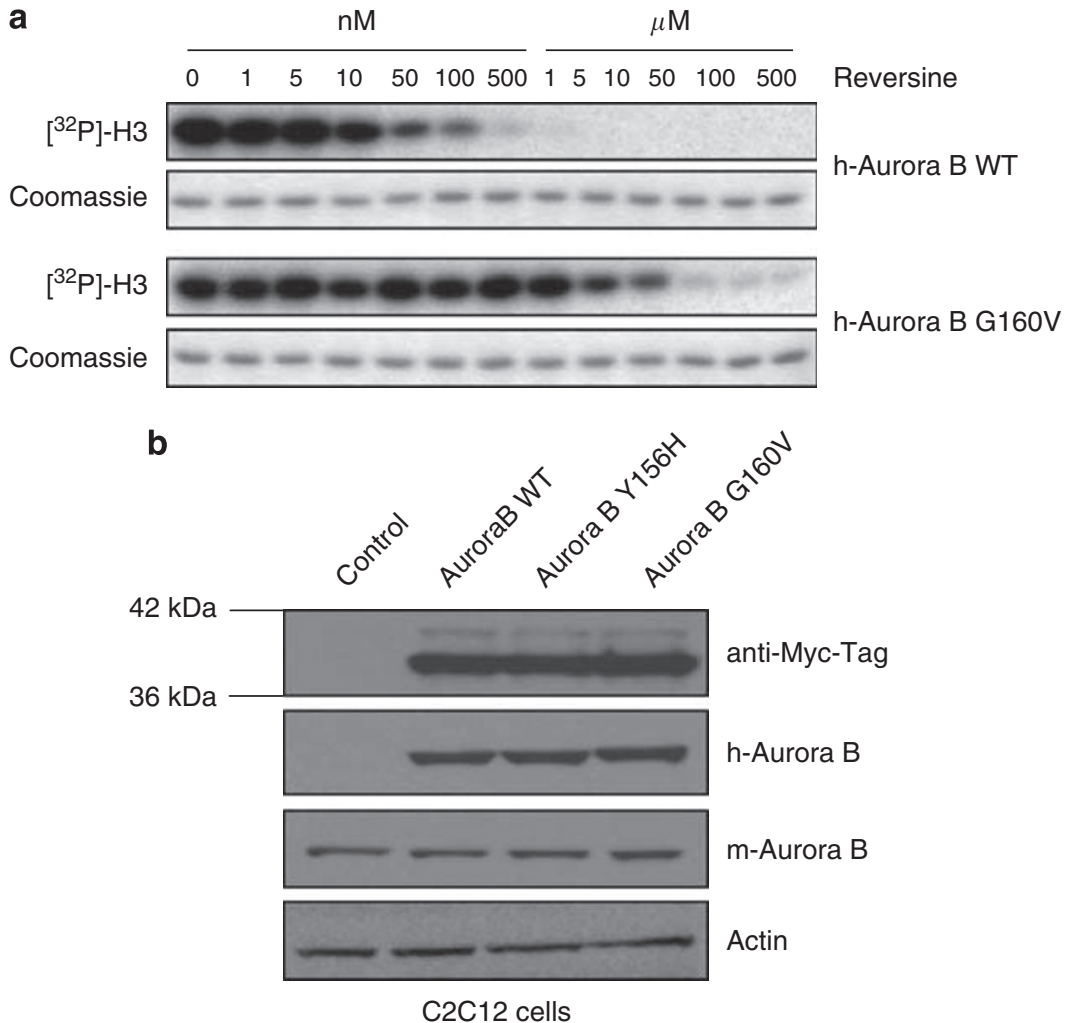

Figure 3 The Aurora B G160V mutant is resistant to reversine. Human Aurora B:INCENP IN-box wild-type (WT; upper panels) and G160V mutant (lower panel) were incubated at $30^{\circ} \mathrm{C}$ for $1 \mathrm{~h}$ with histone $\mathrm{H} 3$ as a substrate, the indicated growing concentrations of reversine, and $\left[\gamma^{32} \mathrm{P}\right]-\mathrm{ATP}$. DMSO was used as control. The incorporation of radioactive phosphate on histone $\mathrm{H} 3$ was visualized by autoradiography. (a) $\mathrm{C} 2 \mathrm{C} 12$ cells were transfected with Aurora B WT, Aurora B Y156H and Aurora B G160V. The presence of ectopic gene expression was assessed after $48 \mathrm{~h}$ post-trasfection by western blot analysis using both an anti-Myc-tag antibody and anti-Aurora B antibody. An antiactin antibody was used as loading control. (b) $\mathrm{C} 2 \mathrm{C} 12$ cells were transfected with Aurora B WT, Aurora B Y156H and Aurora B G160V as indicated. After $48 \mathrm{~h}$, cells were treated with reversine $50 \mathrm{nM}$ for further $72 \mathrm{~h}$ and typical western blot was performed to evaluate the protein levels of ectopic genes

capability of reversine was mediated through the inhibition of Aurora B, the ectopic expression of a drug-resistant Aurora B mutant should maintain the myoblast state despite the presence of reversine. By contrast, if reversine effects were through another target, the expression of the drug-resistant Aurora B mutants should have no effect.

Recently, we have described two mutations in the active site of Aurora B, namely $\mathrm{G} 160 \mathrm{~V}$ and $\mathrm{Y} 156 \mathrm{H}$, which render it resistant to ZM447439, hesperadin, VX-680 and MLN-8054. ${ }^{23}$ On the basis of the $3 \mathrm{D}$ structure of the complex between reversine and Aurora $\mathrm{B},{ }^{9}$ we reasoned that these mutants should also be resistant to reversine. To prove this prediction, we tested the ability of increasing concentrations of reversine to inhibit the activity of recombinant wild-type (WT) human Aurora B:INCENP IN-box complex, or of equivalent complexes bearing the G160V (Figure 3a) or the $\mathrm{Y} 156 \mathrm{H}$ mutation (data not shown), using histone $\mathrm{H} 3$ as an in vitro substrate. In agreement with our prediction, the G160V and $\mathrm{Y} 156 \mathrm{H}$ mutations conferred a $\sim 100$-fold or higher resistance to reversine compared with the WT enzyme (Figure3a, and data not shown).

Next, we used these drug-resistant mutants to directly test the role of Aurora B in the process of dedifferentiation induced by reversine. We transiently transfected $\mathrm{C} 2 \mathrm{C} 12$ cells at $30 \%$ of confluence with plasmids encoding either for WT human Aurora $\mathrm{B}$ or the $\mathrm{Y} 156 \mathrm{H}$ and $\mathrm{G} 160 \mathrm{~V}$ mutants. After $48 \mathrm{~h}$, western blot analysis showed expression of the exogenous Aurora B proteins (Figure $3 \mathrm{~b}$ ). In a parallel experiment, 48-h post-transfection, $50 \mathrm{nM}$ reversine was added for $72 \mathrm{~h}$. We observed that reversine efficiently dedifferentiated the nontransfected controls as shown by the change of cell morphology (Figure 4a). Significantly, C2C12 cells transfected with the drug-resistant mutants did not acquire the round morphology typical of the controls (Figure 4a). In particular, a myotube formation assay was performed to better investigate whether the mutant G160V was sufficient to inhibit the dedifferentiation capabilities of reversine. After $72 \mathrm{~h}$ of reversine treatment, the cells were kept in the same plate for 8 days replacing the medium each $48 \mathrm{~h}$ to permit the myotubes formation. We observed that only the control cells and the cells previously transfected with the resistant mutant were able to form myotubes after reversine exposure. We found that after the transfection with the mutant, about $70 \%$ of cells gave rise myotubes. Not trasfected cells and cells trasfected with Aurora B WT lost completely the myoblast shape, and were not able to form myotubes (Figure 4a).

Furthermore, we also investigated whether the presence of Aurora B, resistant to reversine, would inhibit the whole dedifferentiation-redifferentiation process induced by reversine. After $72 \mathrm{~h}$ of reversine treatment, cells were transferred into the appropriate differentiation medium and cultured for 1 week. Remarkably, in the presence of both mutants, 
a
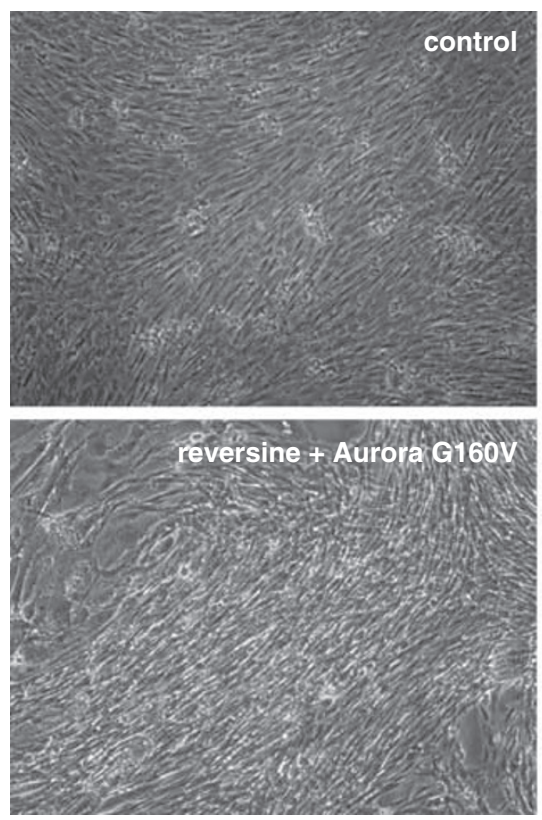

b

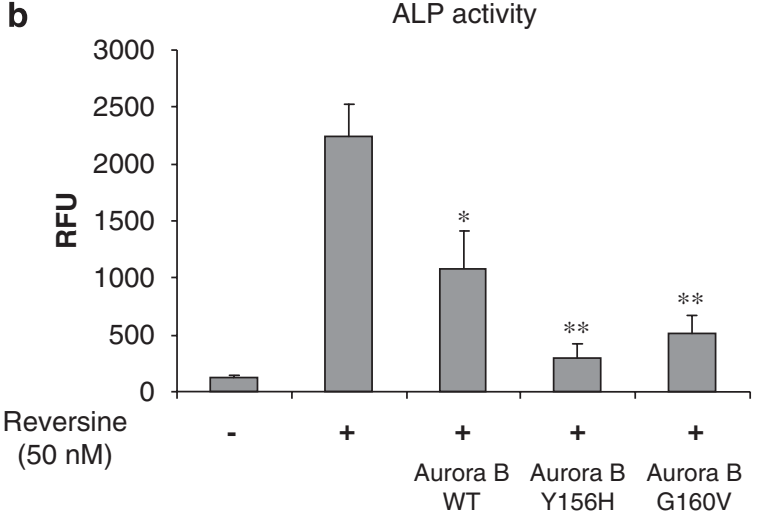

C2C12 cells
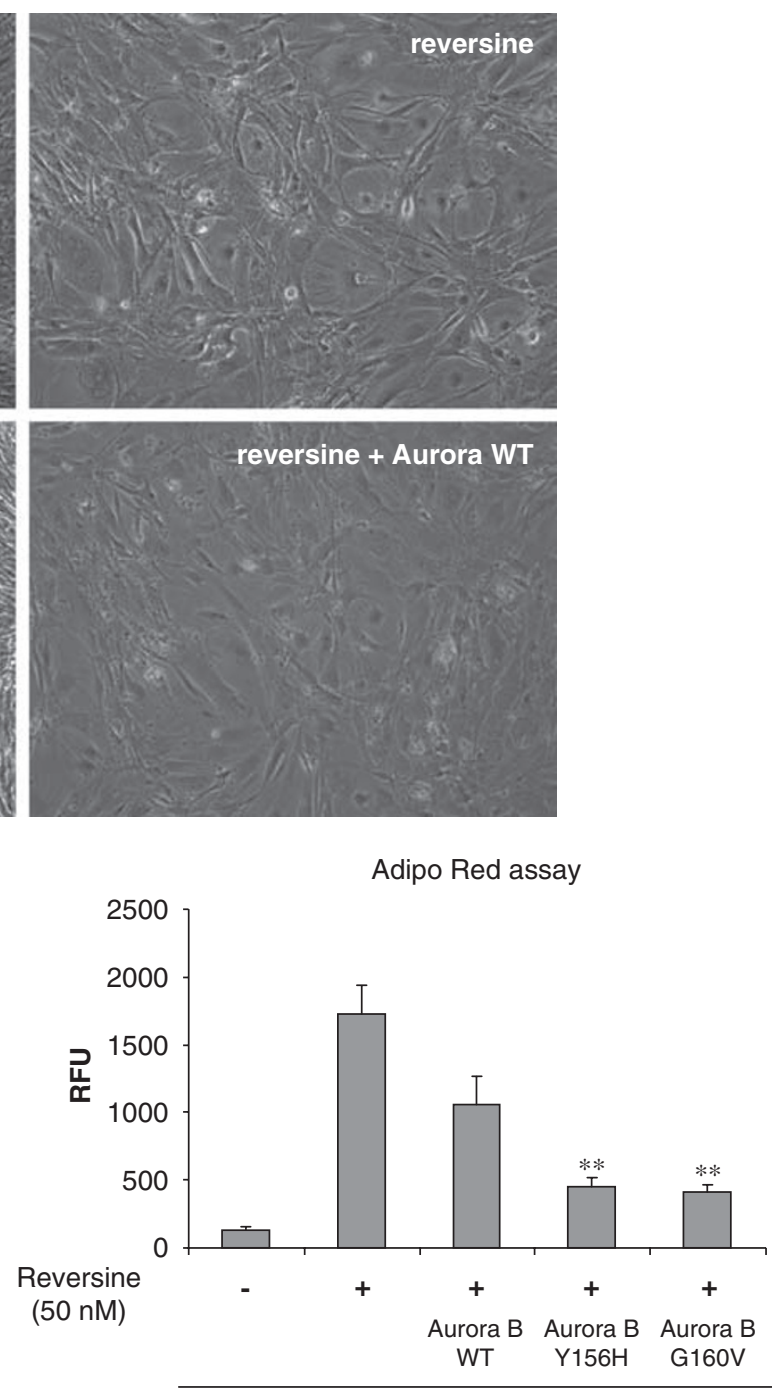

C2C12 cells

Figure 4 Drug-resistant Aurora B kinase inhibits the dedifferentiation process showing positive evidence of differentiation. C2C12 cells were transfected with Aurora B wild type (WT) and Aurora B G160V. After $48 \mathrm{~h}$, cells were treated with reversine $50 \mathrm{nM}$ for further $72 \mathrm{~h}$ and then cultured in growth medium for additional 8 days. (a) Myotubes formation was observed for control cells, as well for the Aurora B G160V tranfected cells. $\mathrm{C} 2 \mathrm{C} 12$ cells treated with reversine (not transfected) and cells transfected with Aurora B WT did not show any evidence of terminal differentiation. (b) $\mathrm{C} 2 \mathrm{C} 12$ cells were transfected with Aurora B WT, Y156H and G160V variants as indicated. After the treatment $(72 \mathrm{~h})$, the cells were cultured in osteogenic-differentiating (ODM) and adipogenic-differentiating media (ADM) for 1 week. ALP activity and lipid droplets content were measured to evaluate the presence of osteoblasts and adipocytes, respectively using a fluorescent substrate system. Data are expressed as relative fluorescence units (RFUs; see Materials and Methods also). Values of RFUs were statistically different with $\left({ }^{*} P<0.05\right)$ and $\left({ }^{* \star} P<0.01\right)$

reprograming of $\mathrm{C} 2 \mathrm{C} 12$ myoblasts induced by reversine was drastically reduced (Figure $4 \mathrm{~b}$ ). The simplest interpretation of these results is that Aurora $B$ kinase activity is essential for the action of reversine. We observed that cells transfected with WT Aurora B displayed only a partial abrogation of the reversine effect, presumably because of a gene dosage effect.

\section{Reversine induces polyploidy and spindle checkpoint} override at high concentration. The results presented so far show that Aurora B kinase is a key player in the nuclear reprograming induced by reversine. Aurora $B$ is involved in multiple mitotic functions, and therefore inhibiting its kinase activity causes a variety of phenotype including chromosome segregation failure, spindle checkpoint override and impairment of cytokinesis. Taken together, these effects result in polyploidy. ${ }^{24}$ In principle, it is conceivable that it is the polyploidy itself, rather than the inhibition of Aurora B per se, which is responsible for the dedifferentiation process. However, we feel that this is unlikely: other agents, which cause polyploidy, including the MEK 1 inhibitor U0126 and the NMMII inhibitor blebbistatin do not cause reprogramming (data not shown). Moreover, reversine induces reprograming at concentrations as low as $20-50 \mathrm{nM}$, whereas significant polyploidy is only observed at higher concentration of reversine (Figure 5a). Similar considerations are true also for the effect on the spindle check point: SP600125, a potent 


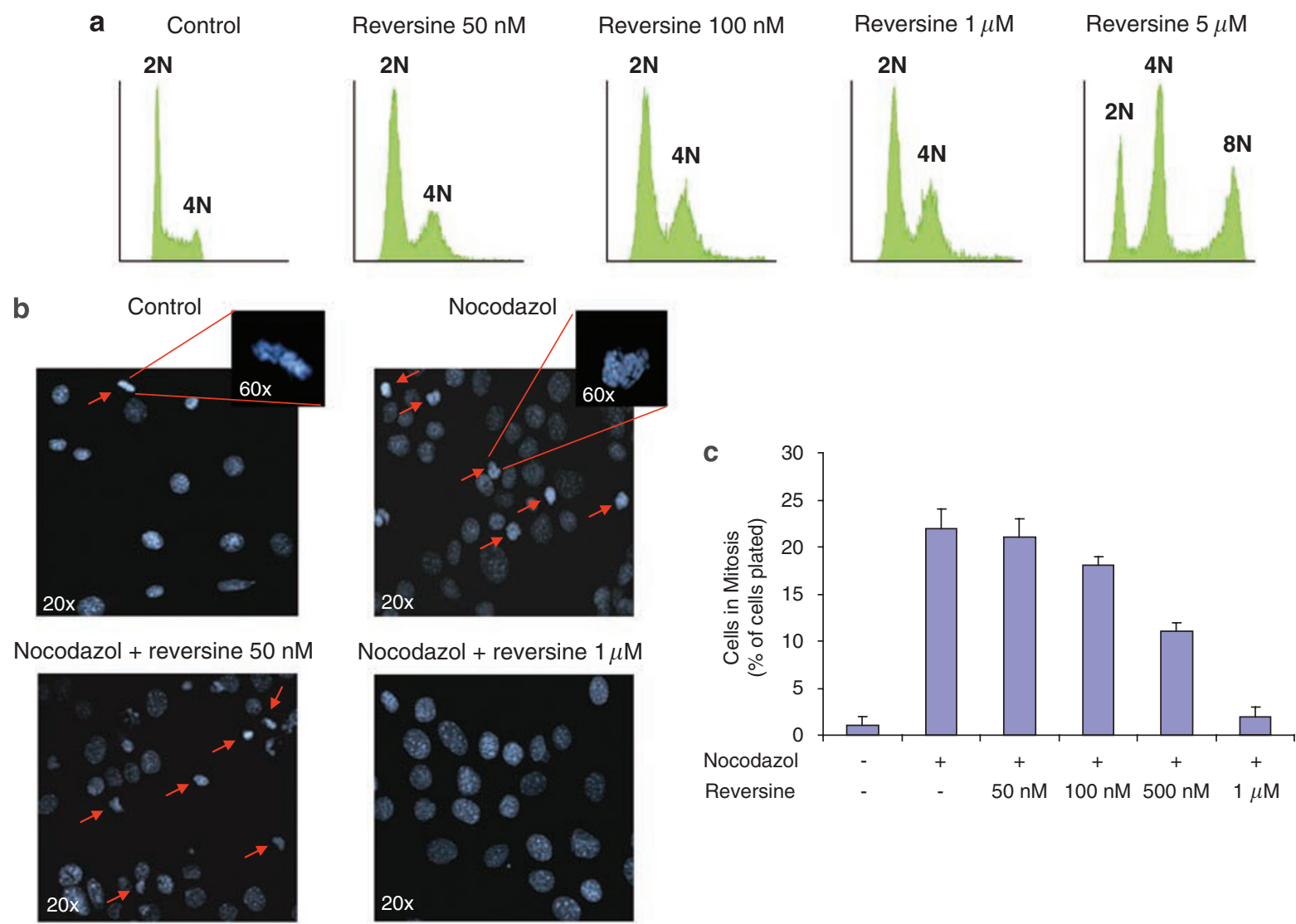

Figure 5 Reversine causes polyploidy and spindle checkpoint overriding at high concentrations. (a) $\mathrm{C} 2 \mathrm{C} 12$ cells were treated for $72 \mathrm{~h}$ with different concentration of reversine as indicated, thus cultured in ODM for additional 7 days. After this period, the cell-cycle analysis of C2C12 cell was performed using propidium lodide with FACS Canto II. (b-c) C2C12 cells were treated with $500 \mathrm{nM}$ nocodazol in presence of increasing concentrations of reversine (as indicated) for $4 \mathrm{~h}$. After this time, the cells were stained with DAPI to analyze the nucleus status and the cells blocked in mitosis were counted. Red arrows in the panel $b$ indicate cells in mitosis

spindle checkpoint overrider does not induce reprograming, and even reversine must be used at concentrations above $1 \mu \mathrm{M}$ to cause spindle checkpoint overriding in $\mathrm{C} 2 \mathrm{C} 12$ myoblasts (Figure $5 b$ and $c$ ).

On balance, therefore, we suspect that the role of Aurora B in maintaining the differentiated state of $\mathrm{C} 2 \mathrm{C} 12$ cells is not linked to its mitotic functions. More likely, the direct involvement of Aurora B on reversine-induced dedifferentiation is based on its role in chromatin remodeling. Consequently, we turned our attention to another key function of Aurora B, namely histone H3 (Ser10) phosphorylation (phospho-Ser10H3) and a possible role in chromatin remodeling. As predicted for a potent Aurora B inhibitor, reversine does indeed inhibit phospho-ser10-H3 in $\mathrm{C} 2 \mathrm{C} 12$ cells (Figure 6a). Furthermore, the inhibitory effect of reversine is significantly reduced following the expression of the drug-resistant Aurora B mutants (Figure 6a) confirming that Aurora $B$ is the bona fide serine 10 kinase, at least in $\mathrm{C} 2 \mathrm{C} 12$ cells.

Reversine induces remodeling of chromatin at the level of muscle differentiation genes. Myogenesis is a complex process regulated by muscle regulatory factors (MRFs) and their inhibitors (Ids proteins). ${ }^{25}$ As reported by several groups, ${ }^{26-28}$ ectopic expression of MRFs, such as MyoD or myogenin, converts nonmuscle cells into muscle cells, suggesting that these factors play a crucial role both in the induction of muscle differentiation and in the maintenance of the differentiated muscle phenotype. Reversine treatment affects the expression of MRFs; in Figure $6 \mathrm{~b}-\mathrm{c}$, we show an evident downregulation of the mRNA levels coding for $M y o D$, myogenin and myogenic factor-5 (Myf5) after reversine treatment. Interestingly, we also observed that the expression of Id1, a known inhibitor of myogenesis, ${ }^{25}$ increased considerably after the treatment (Figure 6b, lower right panel). The treatment of myoblasts with the other Aurora inhibitors also caused a relevant dowregulation of $M y o D$ and $M y f 5$, although, on the other hand, appeared the upregulation of the $I d 1$ expression (Figure 6c), suggesting a common mechanism of action for the three drugs, most likely triggered by the inhibition of Aurora B kinase. In fact, reversine treatment in the presence of Aurora $B$ kinase-resistant mutants did not lead to the downregulation of $M y o D$ expression compared with the untreated cells of with cells trasfected with Aurora B WT (Figure 6b).

Apparently, Aurora B inhibitors and reversine can cause not only the repression but also, with similar kinetics, the activation of genes. To elucidate the putative common molecular event that is at the core of both activation and repression of genes, we analyzed by chromatin immunoprecipitation (ChIP) histone modifications at the level of the 
a

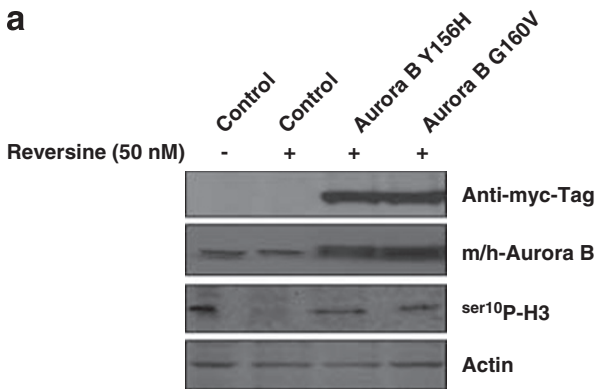

C

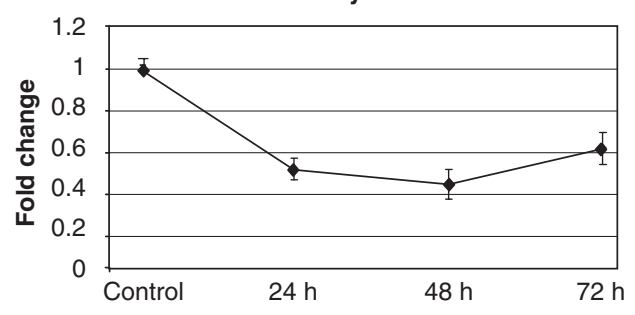

Myogenin

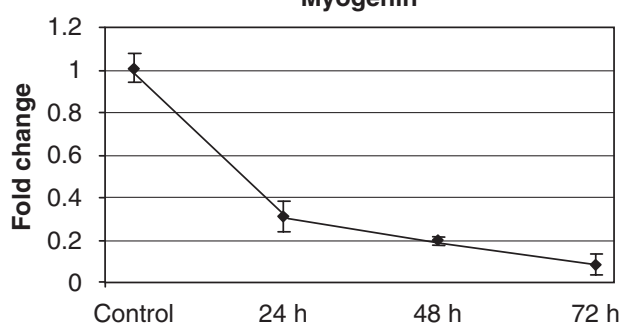

b
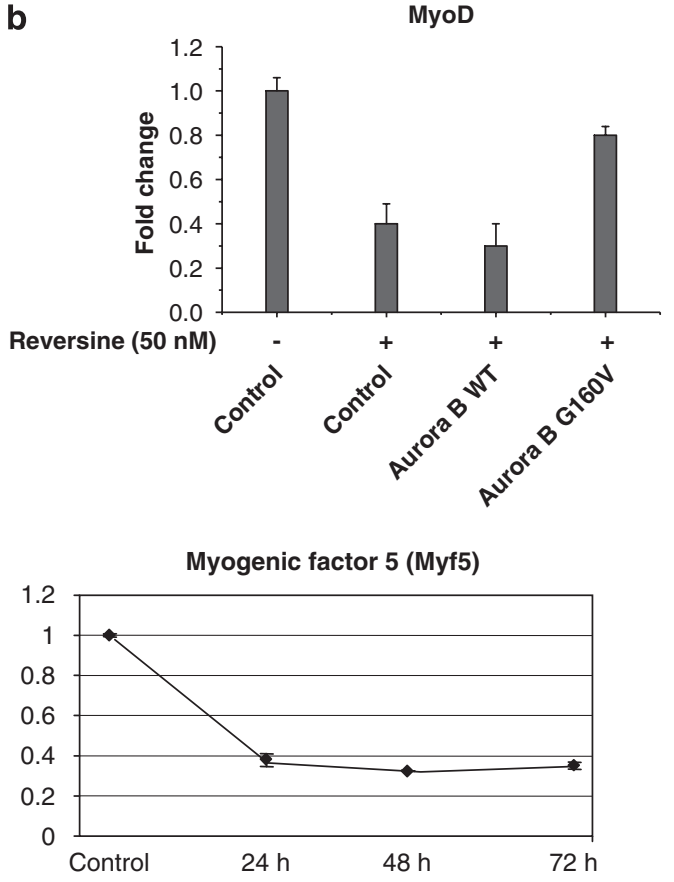

Id1

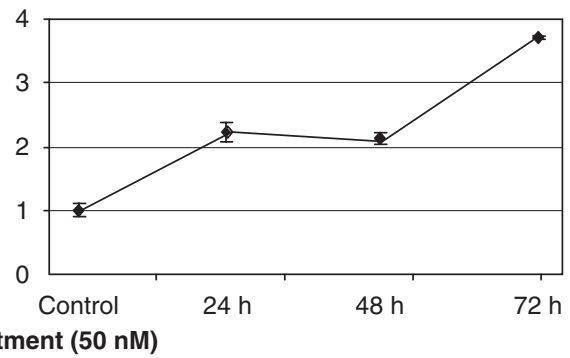

d MyoD

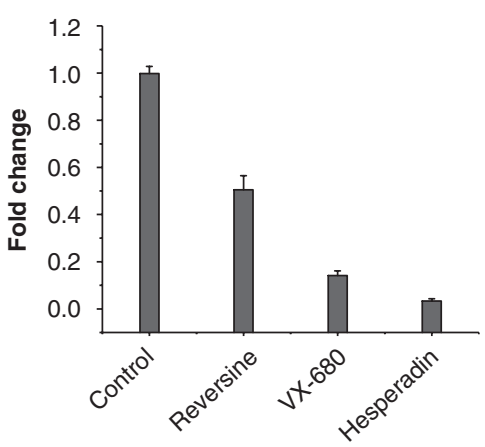

Myf5

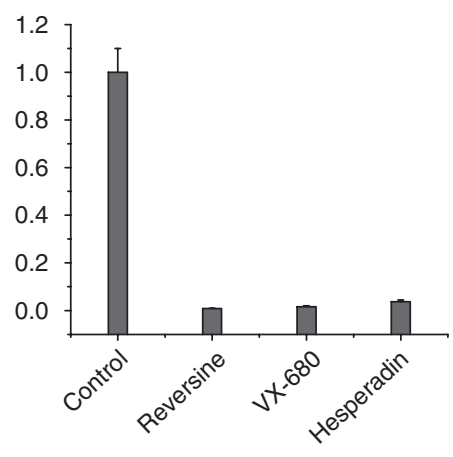

Id1

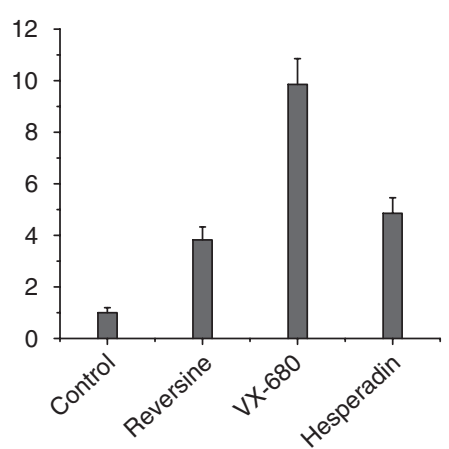

Figure 6 Reversine inhibits histone $\mathrm{H} 3$ phosphorylation on Ser10 and induces the downregulation of MRFs expression . (a) $\mathrm{C} 2 \mathrm{C} 12$ trasfected with Aurora B mutants were treated with $50 \mathrm{nM}$ of reversine for $48 \mathrm{~h}$. After the treatment, the Ser10-H3 phosphorylation status was analyzed by western blot. Anti-Myc and anti-Aurora antibodies were used as transfection control, whereas actin was used as loaded control. (b) MyoD mRNA levels were evaluated in untreated cells, cells treated with reversine and in cells previously transfected with Aurora B G160V, Aurora B wild type (WT), and then treated with reversine for $72 \mathrm{~h}$. (c) C2C12 cells were treated with $50 \mathrm{nM}$ of reversine for 24,48 and $72 \mathrm{~h}$. MRFs and Id1 expressions were analyzed using the real-time PCR with Taqman (MyoD) and SYBR green technologies (Myogenin, Myf5 and Id1). MyoD mRNA levels were normalized to 18S mRNA levels. Myf5, myogenin and Id1 mRNA levels were normalized using Gapdh. The untreated C2C12 cells were used as standard to calculate the fold enrichment. (d) C2C12 cells were treated with $500 \mathrm{nM}$ of reversine, VX-680 and hesperadine for $72 \mathrm{~h}$. MRFs and Id1 expressions were analyzed using the real-time PCR with Taqman (MyOD) and SYBR green technologies (Myogenin, Myf5 and Id1)

MyoD, Myogenin and Id1 promoters. In essence, at the level of the repressed genes (MyoD and Myogenin), we observed the expected inhibition of phospho-Ser10 but no other reversine dependent change, neither in the overall $\mathrm{H} 3$ acetylation, nor methylation (Lys4 and Lys9 were analyzed; Figure 7). Interestingly, but not surprisingly, the dual 

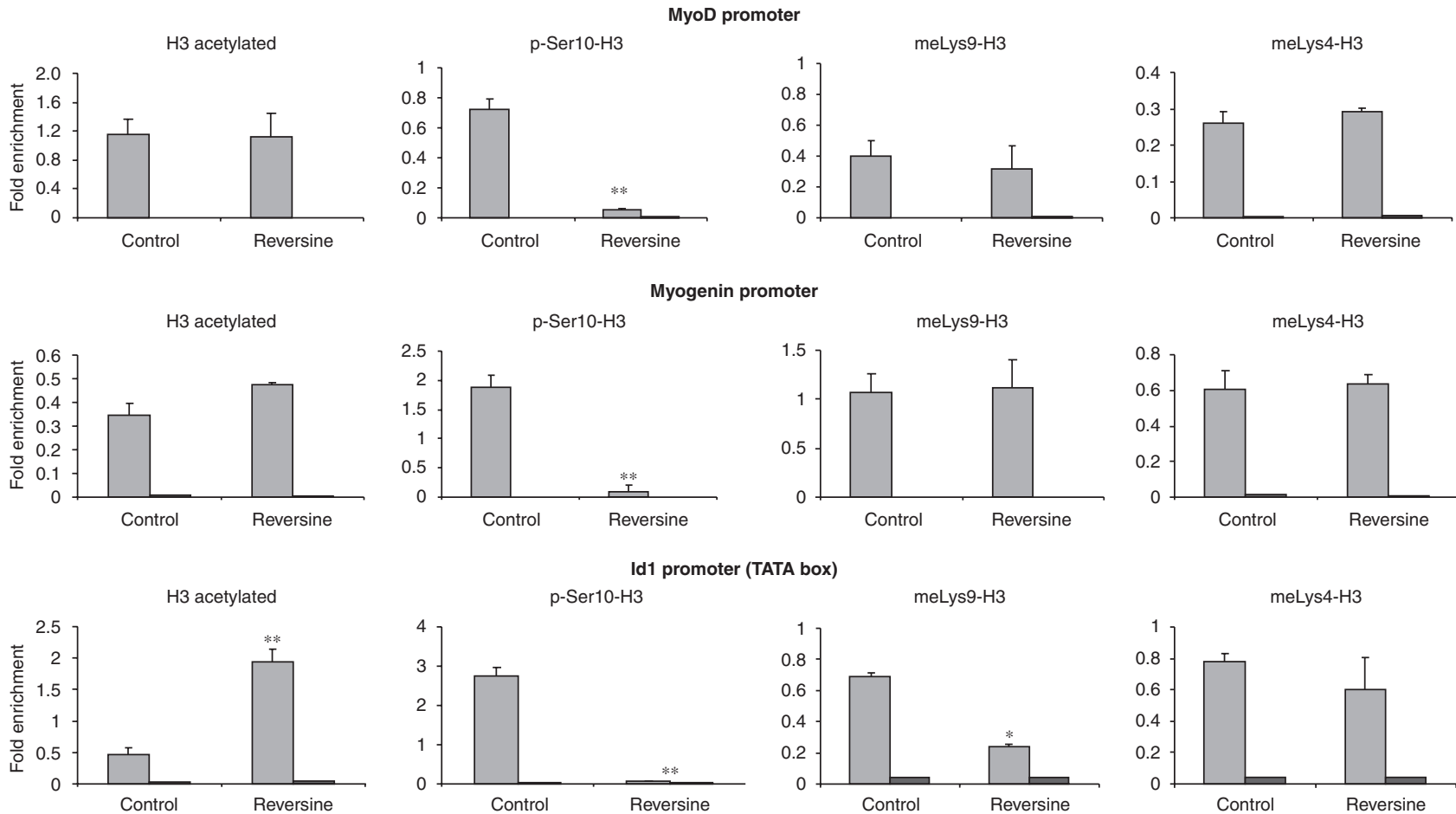

Figure 7 Aurora B is involved in affecting chromatin status. Chromatin immunoprecipitation analysis was performed on $\mathrm{C} 2 \mathrm{C} 12$ cells treated with reversine $50 \mathrm{nM}$ Polyclonal antibodies against $\mathrm{H} 3$ acetylated at lysine 9 and 14, against phospho-Ser10-H3, against dymethil Lys $9-\mathrm{H} 3$ and against dymethil Lys 4-H3 were used to precipitate the protein-chromatin complex. The DNA was purified, and specific regions of mouse MyoD, Myogenin and Id1 promoters were analyzed using the real-time PCR (see Materials and Methods). Rabbit IgG was used as control of the assay specificity (purple barr). Asterisks indicate the values of fold enrichment statistically different with $\left({ }^{\star} P<0.05\right)$ and $\left({ }^{\star \star} P<0.01\right)$

modification of acetyl Lys14 and phospho-Ser10 that represent a marker of gene induction ${ }^{29}$ was drastically reduced in the genes repressed by reversine (Figure 8). This result is in agreement with the findings of Mal et al. ${ }^{30}$ who reported that the presence of phospho-Ser10 at the level of myogenin promoter is a marker of active chromatin. Therefore, it is likely that the reversine causes a decrease in the expression of the myogenin and MyoD genes by inhibiting the phospho-Ser10H3. In contrast to the repressed genes, the pattern of histone modification at the promoter level of the induced gene Id1 was drastically changed following the treatment with reversine. We not only observed the expected inhibition of phospho-Ser10 but also a significant increase of overall $\mathrm{H} 3$ acetylation as well as a decrease of the Lys9 methylation.

In summary, it appears that the common feature after treatment with reversine is the drastic reduction of phosphoSer10-H3 on all the promoters analyzed (Figure 7), as expected for a potent Aurora B kinase inhibitor. Surprisingly, inhibition of phospho-Ser10-H3 leads to opposite effects in Id1 gene (induction) and in $\mathrm{MyoD}$ and myogenin (repression). Recently, Sabbattini et al. ${ }^{17}$ reported the results that are in line with our observations. These authors described a new role of Aurora B kinase in the repression of genes in postmitotic differentiated cells. Specifically, they reported that phosphoSer10 could be a marker of gene repression. Here, We show that the Id1 gene is induced as a consequence of Aurora $B$ inhibition, and the chromatin at the level of its promoter is drastically remodeled with markers typical of active genes (increase in acetylation, decrease of Lys9 methylation). It is likely that Aurora B associates with different protein complexes to mark active and repressed genes. In the future, it will be important to elucidate the molecular bases for these genespecific effects.

\section{Materials and Methods}

Cell culture, treatment and transfection. $\mathrm{C} 2 \mathrm{C} 12$ myoblasts (ATCC Manassas, VA) were cultured in growth medium consisting of DMEM supplemented with $2 \mathrm{mM}$ glutamine, $100 \mathrm{IU} / \mathrm{ml}$ penicillin, $100 \mu \mathrm{g} / \mathrm{ml}$ streptomycin (Invitrogen Corp., Carlsbad, CA) and 10\% (v/v) FBS (HyClone, South Logan, UT). C2C12 cells were treated with reversine, VX-680, hesperadin, MLN-8054 at a concentration range from $20 \mathrm{nM}$ to $5 \mu \mathrm{M}$, whereas control cells were incubated with $0.01 \%$ DMSO. Treatment was maintained for 48 and/or $72 \mathrm{~h}$ without the growth medium changes. $\mathrm{C} 2 \mathrm{C} 12$ cells were transiently transfected with Lipofectamine 2000 (Invitrogen) as suggested by the manufacturer. The cells were screened for the presence of ectopic gene expression after $48 \mathrm{~h}$ by western blot.

Kinase assays. Recombinant human Aurora $\mathrm{B}^{45-344}$ and human INCENP ${ }^{835-903}$ were expressed and purified as described previously. ${ }^{23}$ Kinase assays were carried out in $30 \mu$ reaction mix containing $50 \mu \mathrm{M}$ ATP, $1 \mathrm{mM} \mathrm{DTT}, 1 \mathrm{mM} \mathrm{Na}_{3} \mathrm{VO}_{4}, 5 \mu \mathrm{Ci}\left[\gamma^{-2} \mathrm{P}\right]$ ATP, $5 \mu \mathrm{g}$ of histone $\mathrm{H} 3$ as substrate, $1 \mu \mathrm{l}$ DMSO or drugs dissolved in DMSO, and $5 \mathrm{nM}$ of WT or G160V mutant Aurora B/INCENP. Reaction mixes were incubated for $1 \mathrm{~h}$ at $30^{\circ} \mathrm{C}$, quenched with SDS-loading buffer and resolved on $14 \%$ SDSpolyacrylamide gel (SDS-PAGE). Incorporation of ${ }^{32} \mathrm{P}$ was visualized by autoradiography.

RNA preparation and quantitative analysis. Total RNA was prepared from $\mathrm{C} 2 \mathrm{C} 12$ cells by using Qiagen's RNeasy ${ }^{\mathbb{R}}$ midi kit (Qiagen Inc., Valencia, CA). $M y O D$ expression was assessed after the treatments as indicated using TaqMan ${ }^{\text {TM }}$ chemistry with the ABI 7700 Prism real-time PCR (RT-PCR) instrument (Applied 
MyoD promoter

H3 acetylated

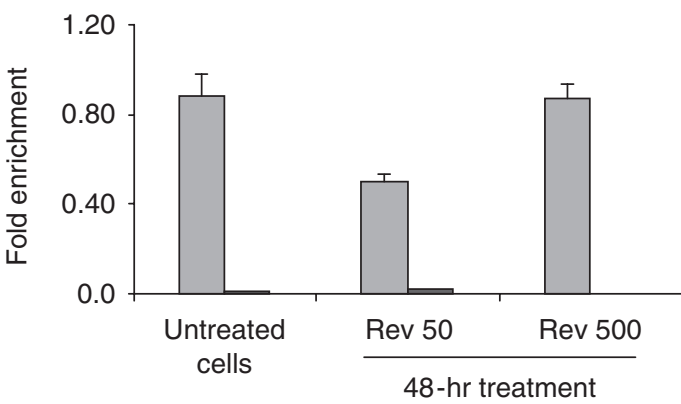

MyoD promoter

p-(Ser10) acetyl-(Lys14)-H3

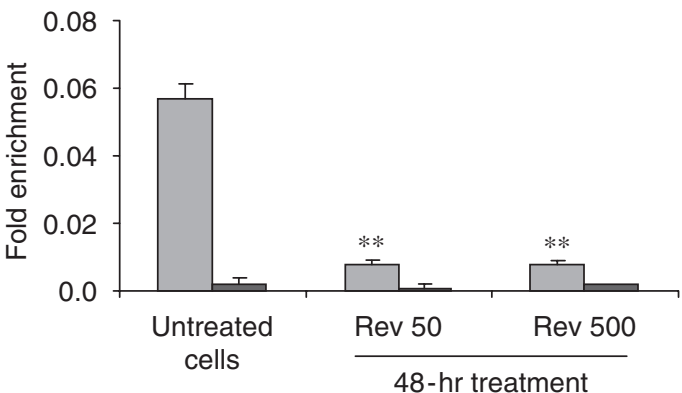

Myogenin promoter

H3 acetylated

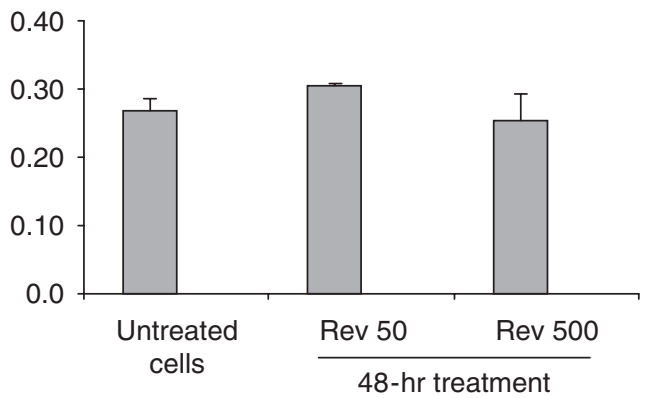

Myogenin promoter

p-(Ser10) acetyl-(Lys14)-H3

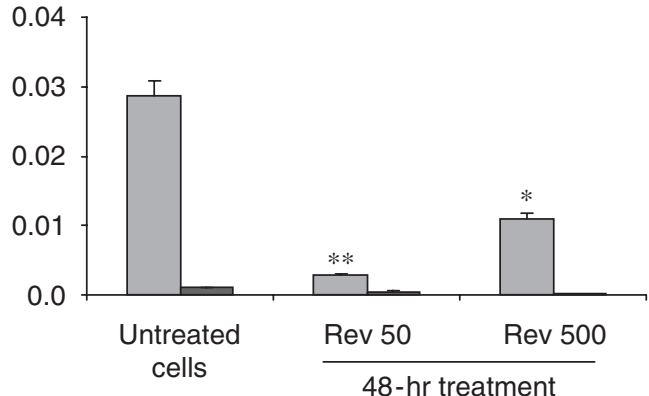

Figure 8 Reversine decreases drastically Ser10-H3 phoshorylation at levels of MRFs genes. Chromatin immunoprecipitation analsysis was performed on $\mathrm{C} 2 \mathrm{C} 12 \mathrm{cells}$ treated with reversine 50 and $500 \mathrm{nM}$ as indicated. Polyclonal antibodies against H3 acetylated at lysine 9 and 14 and against anti-phospho-Ser10-acetyl (K14)-histone H3 were used to precipitate the chromatin-protein complex. The DNA was purified and specific regions of mouse MyoD and myogenin promoter were analyzed using the realtime PCR (see Materials and Methods). Rabbit IgG was used as control of the assay specificity (purple barr). Values obtained for the fold enrichment were statistically different with $\left({ }^{\star} P<0.05\right)$ and $\left({ }^{\star *} P<0.01\right)$

Biosystems, Foster City, CA). The forward and reverse primer $(200 \mathrm{nM})$ sequences for mouse MyoD were $5^{\prime}$-TTCTTCACCACACCTCTGACA-3' and $5^{\prime}$-GCCGT GAGAGTCGTCTTAACTT-3,'respectively, and the probe sequence (100 nM) was $5^{\prime}$-ACAGCCGGTGTGCATTCCAA-3'. Data analysis was performed using $18 \mathrm{~S}$ as internal standard. The forward and reverse primer sequences for mouse $18 \mathrm{~S}$ were $5^{\prime}$-CGGCTACCACATCCAAGGAA- $3^{\prime}$ and $5^{\prime}$-GCTGGAATTACCGCGGCT-3,' respectively, and the probe sequence was $5^{\prime}$ - TGCTGGCACCAGACTTGCCCTC- $3^{\prime}$.

Mouse Myf5 and Myogenin were analyzed as reported previously, ${ }^{31}$ whereas Id 1 was analyzed as reported by Gersbach et $a . .^{32}$ The expression was measured using SYBR green chemistry with the ABI 7700 Prism RT-PCR instrument (Applied Biosystems). The forward and reverse primer sequences of mouse Gapdh used as internal standard were $5^{\prime}$-GGAGATTGTTGCCATCAACGACC-3' and $5^{\prime}$-GGTCATGAGCCCTTCCACAATGC-3,' respectively. Osteopontin, collagen type 1, ap2 and LPL expressions were analyzed with SYBR green method as reported previously. ${ }^{18}$

Dedifferentiation assay. $\mathrm{C} 2 \mathrm{C} 12$ cells were cultured in the presence of reversine, VX-680, hesperadin, MLN-8054 as described. After $72 \mathrm{~h}$ of treatment, compounds were removed and cells were cultured in (ADM or in ODM. Adipogenicinducing medium contained DMEM 10\% FBS, $4.5 \mathrm{~g} / \mathrm{l}$ glucose, $1 \mu \mathrm{M}$ dexamethasone, $0.5 \mathrm{mM}$ isobutylmethylxantine and $10 \mu \mathrm{g} / \mathrm{ml}$ insulin (SigmaAldrich, St. Louis, MO), whereas osteogenic-inducing medium contained DMEM$10 \%$ FBS, $50 \mu \mathrm{g} / \mathrm{ml}$ ascorbic acid-2-phosphate, $0.1 \mu \mathrm{M}$ dexamethasone and $10 \mathrm{mM}$ $\beta$-glicerophosphate (Sigma). For hystochemical analysis, after 7 days of culture in ADM or ODM, cells were fixed with $4 \%$ paraformaldehyde for $15 \mathrm{~min}$ and washed twice with PBS. Cells were then incubated for $2 \mathrm{~h}$ with Oil Red $\mathrm{O}$ reagent (Sigma) to evaluate the presence of adipocytes and with mixture of $0.1 \mathrm{mg} / \mathrm{ml}$ of naphthol AS-MX phosphate (Sigma), $0.5 \% \mathrm{~N}, \mathrm{~N}$-dimethylformamide, $2 \mathrm{mM} \mathrm{MgCl}_{2}$ and $0.6 \mathrm{mg} /$ $\mathrm{ml}$ of fast blue BB salt (Sigma) in $0.1 \mathrm{M}$ Tris- $\mathrm{HCl}, \mathrm{pH} 8.5$, to evaluate the presence of osteoblasts. Cells were examined by phase-contrast microscopy with DFC320 microscope (Leica Microsystems, Wetzlar, Germany). For quantitative analysis, after being cultured for 7 days in ADM, cells were incubated with AdipoRed reagent for $10 \mathrm{~min}$. ALP activity was measured with a fluorescent substrate system (AttoPhos AP; Promega, Madison, WI). After 7 days in ODM, cells were incubated with AttoPhos Substrate (Promega, Madison, WI) for $15 \mathrm{~min}$. Fluorescence was measured as suggested by the manufacturer using Fusion Universal Microplate Analyzer and Envision Microplate Analyzer (Perkin Elmer).

Western blot analysis. Cells were lysed in $50 \mathrm{mM}$ Tris/ $\mathrm{HCl}$ buffer, $\mathrm{pH} 8.0$, containing $150 \mathrm{mM} \mathrm{NaCl}, 1 \%$ Nonidet P-40, $2 \mu \mathrm{g} / \mathrm{ml}$ aprotinin, $1 \mu \mathrm{g} / \mathrm{ml}$ pepstatin, $2 \mu \mathrm{g} / \mathrm{ml}$ leupeptin and $1 \mathrm{mM} \mathrm{Na}_{3} \mathrm{VO}_{4}$. Equal amounts of extracted proteins $(50 \mu \mathrm{g})$ were loaded and separated on SDS-PAGE (Invitrogen), and then transferred onto a nitrocellulose membrane (Schleicher \& Schuell Biosciences, Sandford, ME). Immunodetection was performed using the following primary antibodies: antiMyc-Tag and anti- ser10 P-H3 (Millipore, Billerica, MA), antimouse Aurora B (Becton Dickinson, San Jose, CA) and antimouse/human Aurora B (Abcam Inc., Cambridge, MA).

Cell cycle analysis. $\mathrm{C} 2 \mathrm{C} 12$ cells were incubated with reversine as indicated for $48 \mathrm{~h}$, then the growth medium contained reversine was changed and the cells were cultured with a medium suitable for the development of osteoblstasts (ODM) for $96 \mathrm{~h}$. Cells were fixed in $70 \%$ ethanol over night. After double washing with PBS, cells were labeled with cell-cycle-staining reagent PBS/0.In all, $1 \%$ Triton X-100, $200 \mu \mathrm{g} / \mathrm{ml}$ DNAse-free RNAse, $25 \mu \mathrm{g} / \mathrm{ml}$ propidium iodide (Invitrogen) and incubated at room temperature, in the dark, for $30 \mathrm{~min}$. DNA content was analyzed using FACS Canto II (Becton Dickinson).

Immunofluorescence. In all, $5 \times 10^{4}$ cells were cultured on poly-lysine (Sigma)-coated coverslips and incubated in the presence of nocodazol $500 \mathrm{nM}$ and 
reversine as indicated for $4 \mathrm{~h}$. Cells were fixed in $4 \%$ paraformaldehyde for $20 \mathrm{~min}$ at room temperature. After two washes with PBS, cells were stained with DAPI $0.5 \mu \mathrm{g} /$ $\mathrm{ml}$ for $1 \mathrm{~h}$. The samples were analyzed with Confocal Microscopy with LSM 510 META microscope (Zeiss, Thornwood, NY).

Chromatin immunoprecipitation. Cells ( $10^{6}$ for each antibody) were used to cross-link chromatin using the protocol from Upstate Biotechnology (Milton Keynes, UK) with minor modifications. Briefly, cells were incubated in $1 \%$ formaldehyde for $10 \mathrm{~min}$ at room temperature. Glycine $(0.125 \mathrm{M})$ was added to stop cross-linking. Cross-linked chromatin was sonicated three times for $10 \mathrm{~s}$ at $80 \%$ amplitude (Vibra-Cell sonicator; Sonics and Materials, Meryin/Satigny, Switzerland). Polyclonal antibodies raised against $\mathrm{H} 3$ acetylated at lysine 9 and $14(\alpha \mathrm{H} 3-\mathrm{Ac})$ and against antiphospho-S10-acetyl (K14) histone $\mathrm{H} 3$, both from Millipore, whereas antihistone $\mathrm{H} 3$ dymethil $\mathrm{K} 4$, antihistone $\mathrm{H} 3$ dymethil $\mathrm{K} 9$ and anti-phospho-Ser10-H3 were purchased from Abcam. DNA was purified by phenol-chloroform extraction, and specific regions of the indicated promoters were amplified by RT-PCR using SYBR green method (Applied Biosystem). The primers used for mouse MyoD promoter were $5^{\prime}$-CGCCCCCAGCCTCCCTTTCCA-3' and $5^{\prime}$-TGTCAGAGGTG TGGTGAAGAAA-3'; mouse myogenin promoter was analyzed as reported previously. ${ }^{30}$ The primers used to analyze the TATA box of mouse Id1 promoter were $5^{\prime}$-CTTATAAAAGACTGGCTCCAGC-3' and $5^{\prime}$-GGAGGCTGAGAACA GAAACAGAGTGTG-3' To calculate the fold enrichment, a previously published method was used. ${ }^{33}$

Statistical analysis. Statistical analysis was performed by the analysis of variance (ANOVA) test using Origin 6.1 software for Windows (Microcal Software Inc., Northempton, MA).

Acknowledgements. We are very grateful to Dr. Fabio Formiggini and to Dynamic Imaging Microscopy facility of CEINGE Biotecnologie Avanzate for the help with confocal microscopy. SST is a Cancer Research UK senior fellow.

1. Hochedlinger K, Jaenisch R. Nuclear reprogramming and pluripotency. Nature 2006; 441 1061-1067.

2. Cowan CA, Atienza J, Melton DA, Eggan K. Nuclear reprogramming of somatic cells after fusion with human embryonic stem cells. Science 2005; 309: 1369-1373.

3. Takahashi K, Yamanaka S. Induction of pluripotent stem cells from mouse embryonic and adult fibroblast cultures by defined factors. Cell 2006; 126: 663-676.

4. Wernig M, Meissner A, Foreman R, Brambrink T, Ku M, Hochedlinger $\mathrm{K}$ et al. In vitro reprogramming of fibroblasts into a pluripotent ES-cell-like state. Nature 2007; 448: 318-324

5. Maherali N, Sridharan R, Xie W, Utikal J, Eminli S, Arnold K et al. Directly reprogrammed fibroblasts show global epigenetic remodeling and widespread tissue contribution. Cell Stem Cell 2007; 1: 55-70.

6. Odelberg SJ, Kollhoff A, Keating MT. Dedifferentiation of mammalian myotubes induced by msx1. Cell 2000; 103: 1099-1109.

7. Chen S, Zhang Q, Wu X, Schultz PG. Ding dedifferentiation of lineage-committed cells by a small molecule. J Am Chem Soc 2004; 126: 410-411.

8. Anastasia L, Sampaolesi M, Papini N, Oleari D, Lamorte G, Tringali C et al. Reversinetreated fibroblasts acquire myogenic competence in vitro and in regenerating skeletal muscle. Cell Death Differ 2006; 13: 2042-2051.

9. D'Alise AM, Amabile G, lovino M, Di Giorgio FP, Bartiromo M, Sessa F et al. Reversine, a novel Aurora kinases inhibitor, inhibits colony formation of human acute myeloid leukemia cells. Mol Cancer Ther 2008; 7: 1140-1149.

10. Barr AR, Gergely F. Aurora-A: the maker and breaker of spindle poles. J Cell Sci 2007; 120 2987-2996.
11. Vader G, Cruiisen CW, van Harn T, Vromans MJ, Medema RH, Lens SM. The chromosomal passenger complex controls spindle checkpoint function independent from its role in correcting microtubule kinetochore interactions. Mol Biol Cell 2007; 18 : 4553-4564.

12. Musacchio A, Salmon ED. The spindle-assembly checkpoint in space and time. Nat Rev Mol Cell Biol 2007; 8: 379-393.

13. Fischle W, Tseng BS, Dormann HL, Ueberheide BM, Garcia BA, Shabanowitz $\mathrm{J}$ et al. Regulation of HP1-chromatin binding by histone $\mathrm{H} 3$ methylation andphosphorylation. Nature 2005; 438: 1116-1122.

14. Terada Y. Aurora-B/AIM-1 regulates the dynamic behavior of HP1alpha at the G2-M transition. Mol Biol Cell 2006; 17: 3232-3241.

15. Jenuwein T, Allis CD. Translating the histone code. Science 2001; 293: 1074-1080.

16. Williams L, Zhao J, Morozova N, Li Y, Avivi Y, Grafi G. Chromatin reorganization accompanying cellular dedifferentiation is associated with modifications of histone $\mathrm{H} 3$, redistribution of HP1, and activation of E2F-target genes. Dev Dyn 2003; 228: 113-120.

17. Sabbattini P, Canzonetta C, Sjoberg M, Nikic S, Georgiou A, Kemball-Cook G et al. A novel role for the Aurora B kinase in epigenetic marking of silent chromatin in differentiated postmitotic cells. EMBO J 2007; 26: 4657-4669.

18. Chen S, Takanashi S, Zhang Q, Xiong W, Zhu S, Peters EC et al. Reversine increases the plasticity of lineage-committed mammalian cells. Proc Natl Acad Sci USA 2007; 104: 10482-10487.

19. Cohen P, Goedert M. GSK3 inhibitors: development and therapeutic potential. Nat Rev Drug Discov 2004; 3: 479-487.

20. Hauf S, Cole RW, LaTerra S, Zimmer C, Schnapp G, Walter R et al. The small molecule hesperadin reveals a role for Aurora $B$ in correcting kinetochore-microtubule attachment and in maintaining the spindle assembly checkpoint. J Cell Biol 2003; 161: 281-294.

21. Harrington EA, Bebbington D, Moore J, Rasmussen RK, Ajose-Adeogun AO, Nakayama T et al. VX-680, a potent and selective small-molecule inhibitor of the Aurora kinases, suppresses tumor growth in vivo. Nat Med 2004; 10: 262-267.

22. Manfredi MG, Ecsedy JA, Meetze KA, Balani SK, Burenkova O, Chen W et al. Antitumor activity of MLN8054, an orally active small-molecule inhibitor of Aurora A kinase. Proc Nat Acad Sci USA 2007; 104: 4106-4111.

23. Girdler F, Sessa S, Patercoli S, Villa F, Musacchio A, Taylor S. Molecular basis of drug-resistance in Aurora kinases. Chem Biol 2008; 15: 552-562.

24. Ditchfield C, Johnson VL, Tighe A, Ellston R, Haworth C, Johnson T. Aurora B couples chromosome alignment with anaphase by targeting BubR1, Mad2, and Cenp-E to kinetochores. J Cell Biol 2003; 161: 267-280.

25. Jen $Y$, Weintraub $H$, Benezra R. Overexpression of Id protein inhibits the muscle differentiation program: in vivo association of Id with E2A proteins. Genes Dev 1992; 6 : 1466-1479.

26. Braun T, Buschhausen-Denker G, Bober E, Tannich E, Arnold HH. A novel human muscle factor related to but distinct from MyoD1 induces myogenic conversion in 10T1/2 fibroblasts. EMBO J 1989; 8: 701-709.

27. Davis $\mathrm{RL}$, Weintraub $\mathrm{H}$, Lassar $\mathrm{AB}$. Expression of a single transfected $\mathrm{cDNA}$ converts fibroblasts to myoblasts. Cell 1987; 51: 987-1000.

28. Tapscott SJ, Davis RL, Thayer MJ, Cheng PF, Weintraub H, Lassar AB. MyoD1: a nuclea phosphoprotein requiring a Myc homology region to convert fibroblasts to myoblasts. Science 1988; 242: 405-411.

29. Clayton AL, Rose S, Barratt MJ, Mahadevan LC. Phosphoacetylation of histone H3 on $c$-fos- and c-jun-associated nucleosomes upon gene activation. EMBO J 2000; 19 3714-3726.

30. Mal A, Harter ML. MyoD is functionally linked to the silencing of a muscle-specific regulatory gene prior to skeletal myogenesis. Proc Natl Acad Sci USA 2003; 100 : $1735-1739$

31. Calhabeu F, Lafont J, Le Dreau G, Laurent M, Kazazian C, Schaeffer L et al. NOV/CCN3 impairs muscle cell commitment and differentiation. Exp Cell Res 2006; 312: 1876-1889.

32. Gersbach CA, Byers BA, Pavlath GK, García AJ. Runx2/Cbfa1 stimulates transdifferentiation of primary skeletal myoblasts into a mineralizing osteoblastic phenotype. Exp Cell Res 2004; 300: 406-417.

33. Litt MD, Simpson M, Recillas-Targa F, Prioleau MN, Felsenfeld G. Transitions in histone acetylation reveal boundaries of three separately regulated neighboring loci. EMBO J 2001; 20: 2224-2235.

\section{Supplementary Information accompanies the paper on Cell Death and Differentiation website (http://www.nature.com/cdd)}

